\title{
Cytomegalovirus-associated supraglottic mass in a patient on immunosuppressive therapy
}

\author{
K R Anavi, ${ }^{1} \mathrm{MB}$ BCh; C Nel, ${ }^{2} \mathrm{MB}$ ChB, MMed (Anat Path), FC Path (SA) Anat, PG Dip OMH, PG Dip HSE; \\ M J Savage-Reid, ${ }^{2}$ MB ChB, Dip Obst (SA); K E Adzatia, ${ }^{3}$ MB BCh, FCORL (SA); J S Nel, ${ }^{1}$ MB ChB, FCP (SA), Cert ID (SA), DTM\&H \\ ${ }^{1}$ Division of Infectious Diseases, Department of Medicine, School of Clinical Medicine, University of the Witswatersrand, Johannesburg, \\ South Africa \\ ${ }^{2}$ Department of Anatomical Pathology, Faculty of Health Sciences, University of the Witwatersrand, Johannesburg, South Africa; and National \\ Health Laboratory Service, Charlotte Maxeke Academic Hospital, Johannesburg, South Africa \\ ${ }^{3}$ Department of Otorhinolaryngology. Chris Hani Baragwanath Academic Hospital and Faculty of Health Sciences, University of the Witwatersrand, \\ Johannesburg, South Africa
}

Corresponding author: K R Anavi (karli.anavi.21@gmail.com)

\begin{abstract}
A 33-year-old woman on chronic immunosuppressive treatment for rheumatoid arthritis with a history of inhaled methamphetamine use presented with respiratory failure requiring mechanical ventilation for a prolonged period. After being given plasma exchange, pulses of methylprednisolone and a dose of cyclosporine for suspected ANCA (anti-neutrophilic cytoplasmic autoantibodies) vasculitis, she developed an obstructive supraglottic laryngeal mass that required a tracheostomy to bypass. Biopsy findings revealed the mass to be an inflammatory pseudomass secondary to cytomegalovirus (CMV). The mass resolved after several weeks of intravenous ganciclovir therapy. This is an extremely unusual presentation of localised CMV disease, with only two or three similar cases having been reported worldwide.
\end{abstract}

S Afr Med J 2021;111(7):623-626. https://doi.org/10.7196/SAMJ.2021.v111i7.15614

Cytomegalovirus (CMV) is a common opportunistic pathogen in immunocompromised individuals, including those infected with HIV, transplant recipients and patients using immunosuppressive agents. South Africa (SA) has an extremely high seroprevalence of CMV, with positive antibodies detected in 100\% of HIV-infected individuals in rural primary care clinics. ${ }^{[1]}$ Like all herpesviruses, CMV may remain latent after primary infection. Reactivation of CMV replication may not result in CMV disease in the host, and the diagnosis of CMV disease therefore poses a challenge to clinicians. ${ }^{[2]}$ A wide spectrum of disease exists: a 'CMV syndrome' may occur (characterised by fever, myalgia, atypical lymphocytosis and thrombocytopenia), or the disease may be localised to specific organ sites. ${ }^{[3]}$ The most common sites involve the ocular, gastrointestinal, lower respiratory tract and neurological systems. Involvement of the larynx is extremely rare. We present a rare case of tissue-invasive CMV disease of the supraglottic larynx presenting as a mass lesion that obstructed the respiratory tract.

\section{Case report}

A 33-year-old woman presented with type 1 respiratory failure, acute renal failure and diarrhoea. She had a background of seropositive rheumatoid arthritis, for which she had been taking $20 \mathrm{mg}$ prednisone daily for 2 years. She also had a history of using inhaled methamphetamine for several years, with the latest episode 1 week prior to admission. On examination, she was cushingoid in appearance and was in significant respiratory distress. Bronchial breathing and crackles were apparent bilaterally.

Arterial blood gas measurement on admission revealed the patient to be in type 1 respiratory failure with a partial pressure of oxygen of $42.4 \mathrm{mmHg}(5.6 \mathrm{kPa})$ and a partial pressure of carbon dioxide of $23.1 \mathrm{mmHg}(3 \mathrm{kPa})$. Baseline laboratory investigations revealed a serum creatinine level of $1709 \mu \mathrm{mol} / \mathrm{l}$ with an estimated glomerular filtration rate of $2 \mathrm{~mL} / \mathrm{min} / 1.73 \mathrm{~m}^{2}$. She had a normocytic anaemia (haemoglobin $7.1 \mathrm{~g} / \mathrm{dL}$ ). Testing for perinuclear anti-neutrophil cytoplasmic antibodies (p-ANCA) was strongly positive $(29 \mathrm{U} / \mathrm{mL})$. Further results are set out in Table 1. High-resolution computed tomography of her chest showed bilateral lobular areas of air space opacification, sparing the periphery, with associated pleural effusions and septal thickening. Ceftriaxone and azithromycin were initiated as empirical cover for possible bacterial pneumonia.

The patient was intubated and admitted to the intensive care unit (ICU), and acute haemodialysis was commenced. A diagnosis of methamphetamine-induced glomerulonephritis was entertained. After 11 days she was extubated, and then received a short course of potent immunosuppressive therapy including a $600 \mathrm{mg}$ dose of cyclosporine, three pulses of $500 \mathrm{mg}$ methylprednisolone and three sessions of plasma exchange, after which she declined further plasma exchange sessions. Three days after the cyclosporine, she developed grade 4 stridor and was urgently reintubated. Direct laryngoscopy unexpectedly revealed a supraglottic mass (Fig. 1).

A tracheostomy was performed and a biopsy specimen of the mass was taken and submitted for histopathological examination. Haematoxylin and eosin (H\&E) sections revealed mucosal ulceration with underlying inflamed granulation tissue and associated viral cytopathy in keeping with florid CMV infection, with enlarged cells and nucleomegaly (Fig. 2). Occasional basophilic intranuclear bodies and granular intracytoplasmic inclusions were also seen. In addition, CMV immunohistochemical staining of cells was positive (Fig. 3A and B). There were no signs of dysplasia or malignancy. A serum CMV viral load of $460 \mathrm{IU} / \mathrm{mL}$ was noted at treatment initiation. Serological markers were representative of latent infection with a positive IgG and negative IgM. 


\section{Table 1. Baseline laboratory investigations}

\begin{tabular}{|c|c|c|}
\hline Investigations & Results & $\begin{array}{l}\text { Reference } \\
\text { ranges }\end{array}$ \\
\hline White cell count $\left(\times 10^{9} / \mathrm{L}\right)$ & 11.48 & $3.9-12.6$ \\
\hline Haemoglobin $(\mathrm{g} / \mathrm{dL})$ & 7.1 & $11.6-16.4$ \\
\hline $\mathrm{MCV}(\mathrm{fL})$ & 81.4 & $78.9-98.5$ \\
\hline Platelet count $\left(\times 10^{9} / \mathrm{L}\right)$ & 356 & $186-454$ \\
\hline Neutrophils $\left(\times 10^{9} / \mathrm{L}(\%)\right)$ & $10.05(92.5)$ & $1.6-8.30$ \\
\hline Lymphocytes $\left(\times 10^{9} / \mathrm{L}(\%)\right)$ & $0.87(8.0)$ & $1.4-4.5$ \\
\hline Sodium $(\mathrm{mmol} / \mathrm{L})$ & 127 & $136-145$ \\
\hline Potassium (mmol/L) & 7.4 & $3.5-5.1$ \\
\hline Chloride (mmol/L) & 96 & $98-107$ \\
\hline Bicarbonate (mmol/L) & 10 & $23-29$ \\
\hline Urea $(\mathrm{mmol} / \mathrm{L})$ & 48.3 & $2.1-7.1$ \\
\hline Creatinine $(\mu \mathrm{mol} / \mathrm{L})$ & 1709 & $49-90$ \\
\hline HIV ELISA & Negative & - \\
\hline Anti-CCP antibody $(\mathrm{U} / \mathrm{mL})$ & Positive (646.0) & - \\
\hline Antinuclear antibodies & Negative & - \\
\hline $\begin{array}{l}\text { Anti-myeloperoxidase } \\
\text { antibody }(\mathrm{U} / \mathrm{mL})\end{array}$ & Positive (29) & - \\
\hline Rheumatoid factor (IU/mL) & 573 & - \\
\hline \multicolumn{3}{|l|}{ Arterial blood gas } \\
\hline $\mathrm{pH}$ & 7.287 & $7.35-7.45$ \\
\hline $\mathrm{PCO}_{2}(\mathrm{mmHg})$ & 23.1 & $35-45$ \\
\hline $\mathrm{PO}_{2}(\mathrm{mmHg})$ & 42.4 & $>60$ \\
\hline Sodium $(\mathrm{mmol} / \mathrm{L})$ & 123 & $136-145$ \\
\hline Potassium (mmol/L) & 7 & $3.5-5$ \\
\hline Chloride (mmol/L) & 106 & $98-107$ \\
\hline Glucose (mmol/L) & 5.6 & $>4.0$ \\
\hline Lactate (mmol/L) & 0.9 & $<1.5$ \\
\hline $\mathrm{HCO}_{3}(\mathrm{mmol} / \mathrm{L})$ & 12.8 & $24-26$ \\
\hline $\mathrm{BE}(\mathrm{mmol} / \mathrm{L})$ & -14.5 & $-2-+2$ \\
\hline
\end{tabular}

$\mathrm{MCV}=$ mean cell volume; ELISA $=$ enzyme-linked immunosorbent assay; $\mathrm{CCP}=$ cyclic citrullinated peptide; $\mathrm{HCO}_{3}=$ bicarbonate; $\mathrm{BE}=$ base excess.

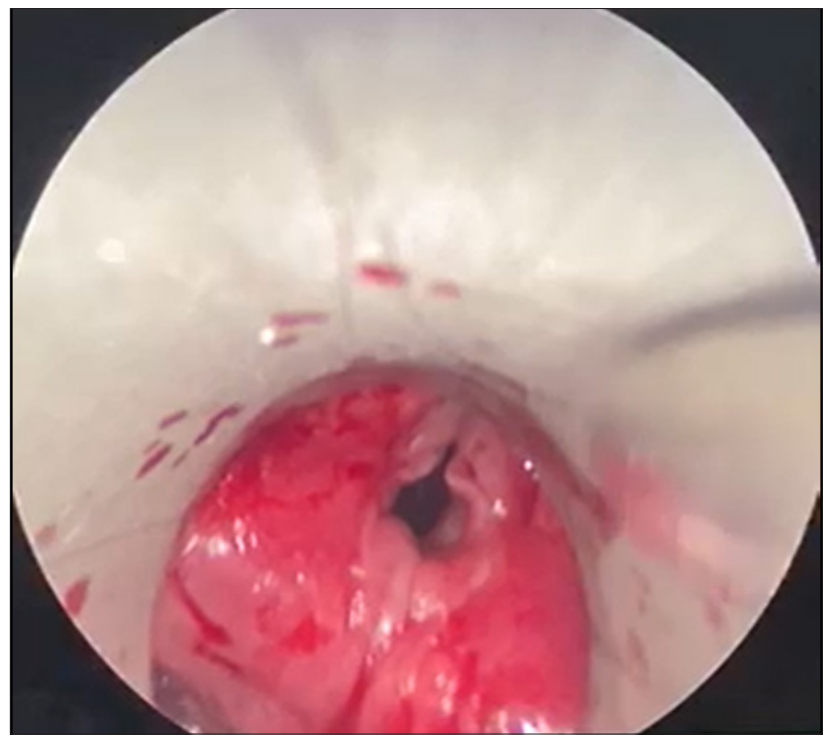

Fig. 1. Direct laryngoscopy showing areas of diffuse inflammation of the supraglottis.

\section{Case management}

Intravenous (IV) ganciclovir at a renally adjusted dose of $100 \mathrm{mg}$ was commenced on alternate days after haemodialysis sessions. The

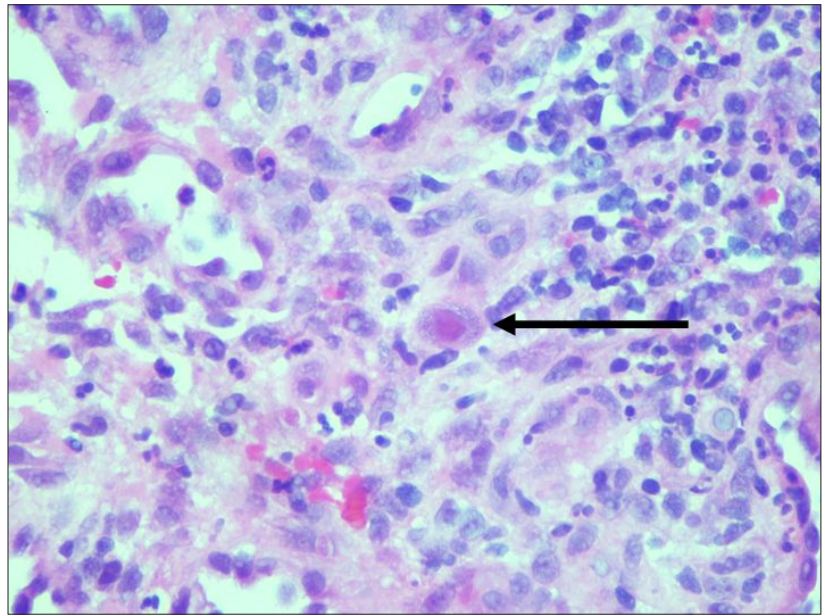

Fig. 2. Inflamed granulation tissue showing neovascularisation, mixed inflammation, reactive fibroblasts and an enlarged cell (arrow) showing evidence of $C M V$ inclusions $(H \& E \times 400)$. ( $C M V=$ cytomegalovirus; $H \& E=$ haematoxylin and eosin.)

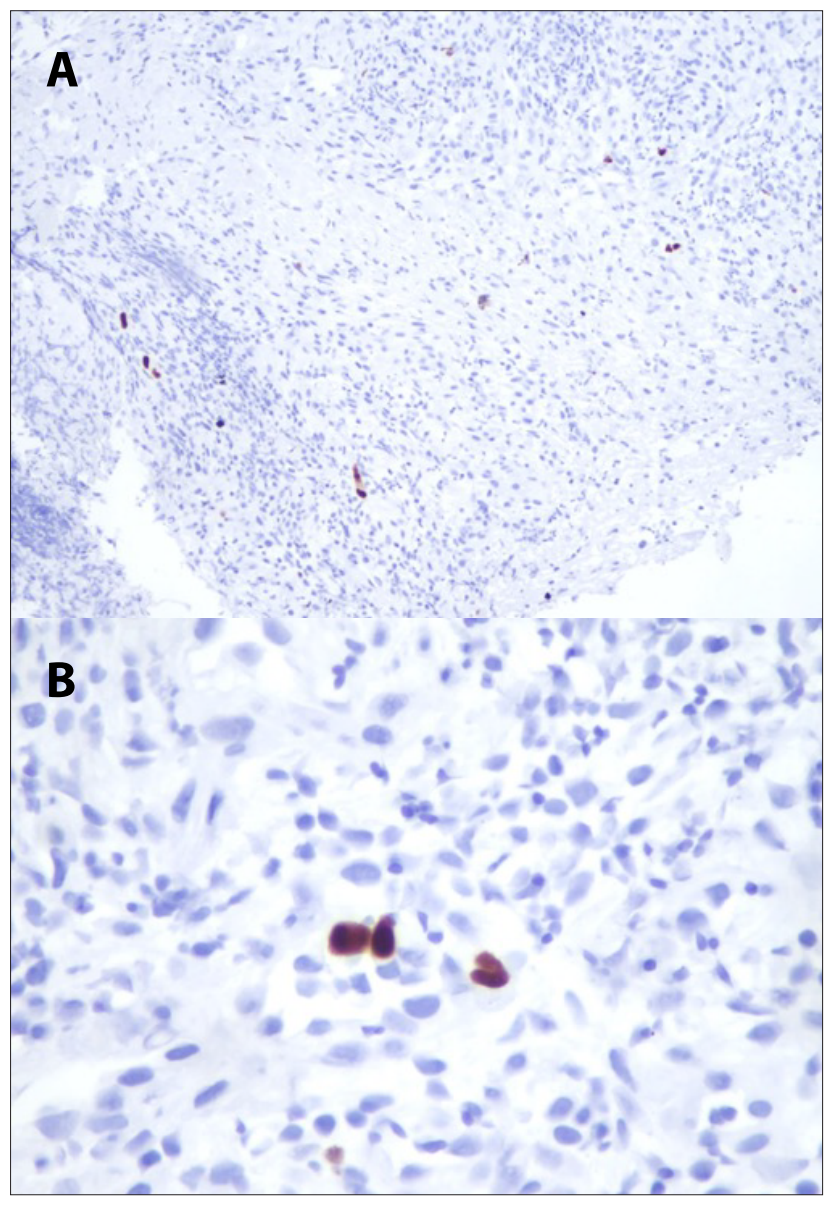

Fig. 3. Strong nuclear staining, confirming the presence of $C M V$ infection within the ulcer bed. A: CMV IHC $\times 100 ; B: C M V I H C \times 400)$. (CMV = cytomegalovirus; $I H C=$ immunohistochemistry. $)$

patient was transferred to a high-care area. CMV viral loads were monitored weekly and ganciclovir was continued until CMV plasma viral loads were undetectable by highly sensitive assay 3 weeks later. Two weeks after the initiation of therapy, repeat imaging by video laryngoscopy showed near-complete resolution of the mass. However, the tracheostomy tube was not removed owing to the development of 
an anterior glottic web with a narrowed airway. Following discharge, readmissions occurred for episodes of intermittent haemoptysis and ongoing dialysis, thought to be related to the patient's ANCA-positive vasculitis. However, there was no recurrence of the CMV mass. Three months after insertion, the tracheostomy tube remained in situ and the patient was awaiting renal replacement therapy in the form of peritoneal dialysis.

\section{Discussion}

CMV is part of the beta-herpesvirus subfamily. ${ }^{[4]}$ After the establishment of latent disease, robust immunity prevents reinfection or reactivation. Primary infection in an immunocompetent host typically results in a mild viral syndrome or is subclinical. ${ }^{[3]}$ However, in immunocompromised hosts, viral replication may reactivate and cause severe disease in various organs. ${ }^{[3]}$

The diagnosis of invasive disease is not straightforward, as viral replication can be subclinical, and the presence of CMV in the blood or in tissue therefore does not necessarily imply CMV disease. ${ }^{[3]}$ Furthermore, particularly in the case of retinal or gastrointestinal involvement, severe disease may occur without significant viral replication being detected in the plasma. ${ }^{[5]}$ In this case the extensive CMV-induced changes and positive immunohistochemistry in the tissue samples, as well as the absence of any other cause for the mass noted histopathologically, support our contention that the occluding supraglottic mass was purely caused by CMV. This case highlights the importance of prompt biopsy of lesions in immunocompromised patients.

In the literature, only a handful of case reports have documented specific laryngeal manifestations of $\mathrm{CMV}^{[6-9]}$ Some reports detail laryngeal ulceration, and to the best of our knowledge only two, possibly three, reports describe distinct mass-like lesions of the larynx caused by CMV. Tinelli et al. ${ }^{[6]}$ described a young HIV-positive female patient with a CD4 count of 38 cells/ $\mu \mathrm{L}$ who developed localised CMV disease with irregular growths of the posterior wall of the hypopharynx. The patient experienced clinical improvement after 3 weeks' treatment with IV ganciclovir; however, she had some clinical recurrence of pharyngeal ulceration after 5 months while on a maintenance dose of $5 \mathrm{mg} / \mathrm{kg} 3$ times a week. Subsequently the maintenance dose was adjusted to long-term daily doses of ganciclovir, with mild improvement of the ulceration. In another case report, Friedman et al. ${ }^{[7]}$ described a patient with no evidence of immunocompromise who presented with airway obstruction caused by a pedunculated CMV subglottic mass. Surgical excision of the mass alone was curative, and there was no need to use ganciclovir.

Akimoto et al.$^{[8]}$ described a patient with nephrotic syndrome on steroids with concurrent active herpes zoster ophthalmicus who developed airway compromise caused by a supraglottic mass of the larynx, presumptively caused by herpes zoster and initially treated as such. Later blood tests revealed positive CMV antigenaemia, after which treatment was changed to IV ganciclovir. It is difficult to assess the cause of the mass, as no histological diagnosis was proven. Despite this, the mass had resolved after 24 days of IV ganciclovir given 3 times a week.

In our case, the finding of a CMV-related laryngeal mass was unexpected. The patient's risk factors included chronic use of lowdose prednisone, a prolonged ICU stay that included mechanical ventilation, ANCA-positive vasculitis, a pulse of methylprednisolone and cyclosporine, and three sessions of plasma exchange.

In a prospective observational study, it was found that CMV reactivation was independently associated with an increased duration of ICU and hospital stay and with prolonged mechanical ventilation. ${ }^{[10]}$ Additionally, other reviews have found that risk factors for opportunistic infection in ANCA-associated vasculitis include aggressiveness of induction therapy, cumulative exposure to steroids, older age and impairment of renal function, especially dialysis dependence, which are all relevant risks in our case (except for age). ${ }^{[11]}$

Another question to answer is why the CMV disease manifested so profoundly in the supraglottic larynx, a highly unusual site. Our patient had used inhaled methamphetamines for several years. This illicit drug promotes airway injury ${ }^{[2]}$ and also has immune-modulating effects. ${ }^{[13]}$ Some consequences include irritation of mucosa causing nonspecific inflammation, release of proinflammatory mediators, and oxidative stress. ${ }^{[14,15]}$ Methamphetamines cause a dysregulated immune response. ${ }^{[13]}$ Infrequent reports of respiratory complications have noted pulmonary hypertension, pulmonary oedema and barotrauma resulting from its inhalation. ${ }^{[12]}$ In addition, the patient had recently been intubated. Some studies have postulated that mechanical abrasion may reactivate latent infection in endothelial cells, particularly those exposed to shear stress. ${ }^{[16,17]}$

The combination of tracheal intubation and inhaled methamphetamine use may explain why the patient's CMV disease was so well localised, though this hypothesis is somewhat speculative. An additional consideration is that certain forms of p-ANCA-positive vasculitis, such as granulomatosis with polyangiitis, may affect the larynx, although there was no evidence of granuloma formation or necrotising vasculitis on the biopsy specimens.

\section{Conclusions}

CMV disease of the larynx is uncommon, and disease manifesting as a mass lesion that obstructs respiration even more so. Our patient's extremely unusual presentation was probably due to a combination of CMV reactivation from profound immunosuppression together with tracheal abrasion and damage from her recent endotracheal intubation and possibly chronic inhaled methamphetamine use.

\section{Declaration. None.}

Acknowledgements. None.

Author contributions. KRA and JSN were the clinicians involved in the management of the patient's care and wrote the initial draft of the case report. MJS-R contributed to the editing of the article and along with $\mathrm{CN}$ contributed to the histopathological images. KEA contributed to the management of the patient's care and the images of the mass.

Funding. None.

Conflicts of interest. None.

Patient consent. The patient consented to the writing of the article and to use of the images.

1. Schaftenaar E, Verjans GM, Getu S, et al. High seroprevalence of human herpesviruses in HIV-infected individuals attending primary healthcare facilities in rural South Africa. PLoS ONE 2014;9(6):e99243 https://doi.org/10.1371/journal.pone.0099243

2. Caliendo AM. Approach to the diagnosis of cytomegalovirus infection. UpToDate, last updated 25 January 2019. https://www.uptodate.com/contents/approach-to-the-diagnosis-of-cytomegalovirusinfection? search=Approach $\% 20$ to $\% 20$ the $\% 20$ diagnosis $\% 20$ of $\% 20$ cytomegalovirus $\% 20$ infection. \&source $=$ search_result $\&$ selectedTitle $=1 \sim 150 \&$ \&usage type $=$ default \&display_rank $=1$ infection. \&source $=$ search
(accessed 15 October 2020).

3. Gandhi MK, Khann R. Human cytomegalovirus: Clinical aspects, immune regulation, and emerging treatments. Lancet Infect Dis 2004;4(12):725-738. https://doi.org/10.1016/S1473-3099(04)01202-2

Arbeitskreis Blut, Untergruppe. Human cytomegalovirus (HCMV) - revised. Transfus Med Hemother 2010;37:365-375. https://doi.org/10.1159/000322141

5. Britt W. Virus entry into host, establishment of infection, spread in host, mechanisms of tissue damage. Britt W. Virus entry into host, establishment of infection, spread in host, mechanisms of tissue damage.
In: Arvin A, Campadelli-Fiume G, Mocarski E, et al., eds. Human Herpesviruses: Biology, Therapy, and Immunoprophylaxis. Cambridge: Cambridge University Press, 2007.

6. Tinelli M, Castelnuovo P, Panigazzi A, D'Andrea F, Caprioglio S. Mass lesions of the larynx due to cytomegalovirus infection in a patient infected with the human immunodeficiency virus. Clin Infect Dis 1995;20(3):726-727. https://doi.org/10.1093/clinids/20.3.726

7. Friedman AD, Maurer WG, Byrd MC, Cook JR, Lorenz RR. A cytomegalovirus-associated mass presenting with laryngeal obstruction. Arch Otolaryngol Head Neck Surg 2006;132(12):1375-1378. https://doi.org/10.1001/archotol.132.12.1375

8. Akimoto T, Yamazaki T, Saito O, Muto S, Kusano E, Nagata D. A supraglottic pseudotumor in an immunocompromised patient with nephrotic syndrome herpes zoster and a cytomegalovirus infection. Clin Med Insights Case Rep 2016;9:61-65. https://doi.org/10.4137/CCRep.S40058 
9. Adland E, Klenerman P, Goulder P, Matthews PC. Ongoing burden of disease and mortality from HIV/ CMV coinfection in Africa in the antiretroviral therapy era. Front Microbiol 2015;6:1016. https://doi org/10.3389/fmicb.2015.01016

10. Heininger A, Haeberle H, Fischer I, et al. Cytomegalovirus reactivation and associated outcome of Heininger A, Haeberle $\mathrm{H}$, Fischer I, et al. Cytomegalovirus reactivation and associated outcom
critically ill patients with severe sepsis. Crit Care 2011;15(2):R77. https://doi.org/10.1186/cc10069

11. Kronbichler A, Jayne DRW, Mayer G. Frequency, risk factors and prophylaxis of infection in ANCAassociated vasculitis. Eur J Clin Invest 2015;45(3):346-368. https://doi.org/10.1111/eci.12410

12. Tashkin DP. Airway effects of marijuana, cocaine, and other inhaled illicit agents. Curr Opin Pulm Med 2001;7(2):43-61. https://doi/10.1097/00063198-200103000-00001

3. Papageorgiou M, Raza A, Fraser S, Nurgali K, Apostolopoulos V. Methamphetamine and its immunemodulating effects, Maturitas 2019;121:13-21. https://doi.org/10.1016/j.maturitas.2018.12.003

14. Mégarbane $\mathrm{B}$, Chevillard $\mathrm{L}$. The large spectrum of pulmonary complications following illicit drug use Features and mechanisms. Chem Biol Interact 2013;206(3):444-451. https://doi.org/10.1016/.cbi.2013.10.011
15. Wilson KC, Saukkonen JJ. Acute respiratory failure from abused substances. J Intensive Care Med 2004;19(4):183-193. https://doi.org/10.1177/0885066604263918

16. Jacobs H, Visser M, Key NS, Goodman JL, Moldow CF, Vercellotti GM. Herpes virus infection of endothelium: New insights into atherosclerosis. Trans Am Clin Climatol Assoc 1992;103:95-104.

17. Vossen R, van Dam-Mieras MCE, Bruggem CA. Cytomegalovirus infection and vessel wall pathology. Intervirology 1996:39(3):213-221. https://doi.org/10.1159/000150497

Accepted 23 March 2021 